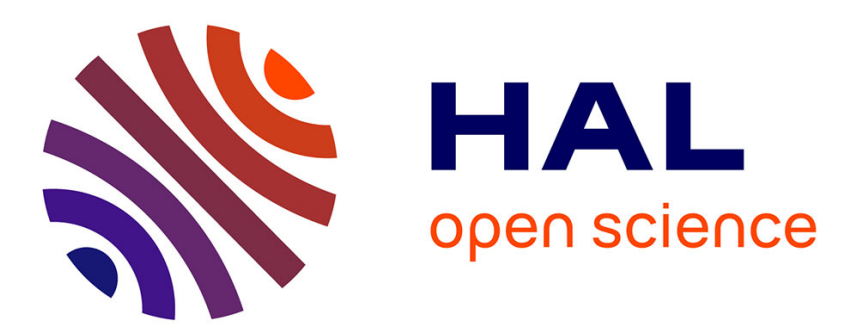

\title{
Detection and Survey of Interface Defects Within a Pavement Structure with Ultrasonic Pulse Echo
}

\author{
Jean Michel Simonin, Géraldine Villain
}

\section{To cite this version:}

Jean Michel Simonin, Géraldine Villain. Detection and Survey of Interface Defects Within a Pavement Structure with Ultrasonic Pulse Echo. MCD2016, 8th International conference on Mechanisms of Cracking and Debonding in Pavements, Jun 2016, NANTES, France. 6p, 10.1007/978-94-024-08676_94. hal-01364068

\author{
HAL Id: hal-01364068 \\ https://hal.science/hal-01364068
}

Submitted on 12 Sep 2016

HAL is a multi-disciplinary open access archive for the deposit and dissemination of scientific research documents, whether they are published or not. The documents may come from teaching and research institutions in France or abroad, or from public or private research centers.
L'archive ouverte pluridisciplinaire HAL, est destinée au dépôt et à la diffusion de documents scientifiques de niveau recherche, publiés ou non, émanant des établissements d'enseignement et de recherche français ou étrangers, des laboratoires publics ou privés. 


\title{
Detection and Survey of Interface Defects within a Pavement Structure with Ultrasonic Pulse Echo
}

\author{
Jean-Michel Simonin, Géraldine Villain \\ LUNAM Université, IFSTTAR, Route de Bouaye, CS4, F-44344 Bouguenais Cedex France \\ jean-michel.simonin@ifsttar.fr
}

\begin{abstract}
A pavement structure, which contains artificial interface defects, has been built on the full scale accelerated pavement testing facility of IFSTTAR in Nantes. This test section is made of two bituminous layers $(8 \mathrm{~cm}$ thick base layer, and $6 \mathrm{~cm}$ thick wearing course), over a granular subbase. Several types of defects have been included at the interface between the two asphalt layers. Rectangular debonded areas of different size (of longitudinal or transversal direction) have been created artificially, using different techniques (sand, textile, absence of tack coat). The construction has been carried out by a road construction company, using standard road works equipment. Then, the pavement fatigue testing facility has been used to apply traffic loading on this pavement, to study the effect of such sliding interfaces on the mechanical behaviour of the pavement, and the evolution of the defects with traffic. The pavement structure has been monitored with several non-destructive methods. The paper presents the survey of the test section with an Ultrasonic Pulse Echo method. This Non Destructive Technique used high frequency wave propagation. It has been able to detect and locate interface defects. The method can also be used to evaluate material properties.
\end{abstract}

Keywords Pavement monitoring, Interface defects, Non-Destructive Technique, Fatigue testing, Ultrasonic Pulse-Echo, Material properties

\section{Introduction}

French roads consist mainly of old bituminous pavements often more than 30 years old. Usually, they have been maintained several times with thin overlays 
(less than $8 \mathrm{~cm}$ thick). In recent years, potholes and alligator cracking has been frequently observed, in particular after periods of heavy rain or freeze/thaw. Frequently, this type of damage is associated with moisture effects linked to interface debonding between the overlays and the old pavement. Such debonding mechanisms reduce the residual life of the pavement, and thus their early detection is a very important issue for pavement maintenance. To detect such interface damage, non-destructive techniques (NDT), such as seismic wave propagation methods, appear as promising approaches.

This paper presented tests performed on a pavement structure with Ultrasonic Pulse Echo (UPE). Shear waves have been used to detect and locate debonding during an experiment carried out on the large pavement fatigue carrousel of IFSTTAR in Nantes. Additional tests, based on compression waves propagation, have been performed to characterize the mechanical behavior of the wearing course.

\section{Description of the full scale experiment}

The test site is located on the pavement fatigue carrousel of IFSTTAR (Figure 1). A $25 \mathrm{~m}$ long test section has been built by a road construction company, using standard equipment. It consists of two bituminous layers $(8 \mathrm{~cm}$ thick base layer, and $6 \mathrm{~cm}$ thick wearing course), over a granular subbase $(30 \mathrm{~cm}$ thick). Several types of defects were intentionally incorporated or at the interface between the two asphalt layers. Figure 2 presents a photograph of the debonded areas before the wearing course construction (2a) and a map of the experimental section, with the location of the different defects $(2 b)$.

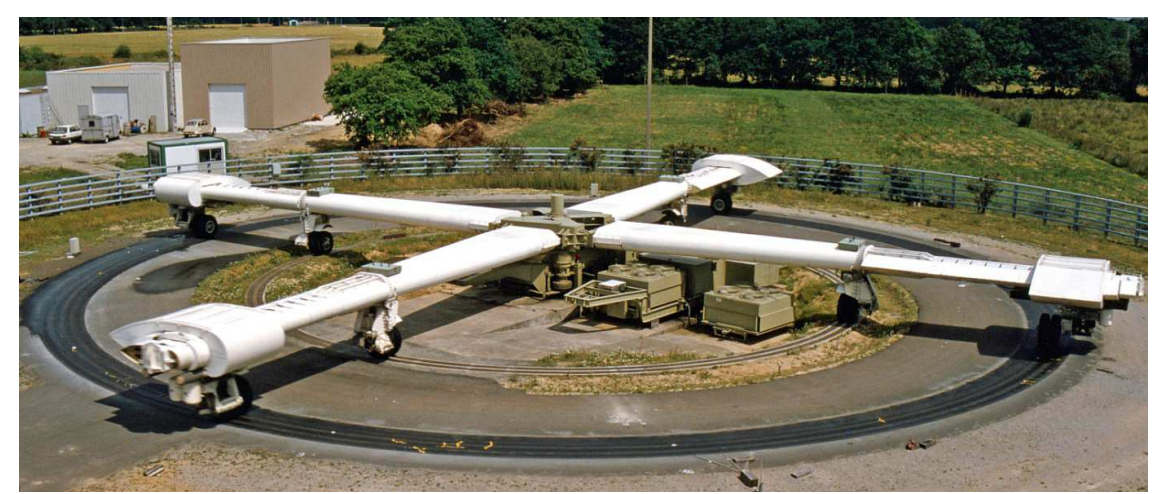

Fig. 1 The pavement fatigue carrousel of IFSTTAR

Three techniques were used to simulate different level of sliding interface: without tack coat, textile and sand. Defect I10 is narrower than the wheel-path $(0.5 \mathrm{~m}$ vs 
$1 \mathrm{~m})$ for evaluating the transversal extension of the defect. Defects I1, I2, I3 and I11, I12, I13 are wider than the wheel-path to study a longitudinal extension.
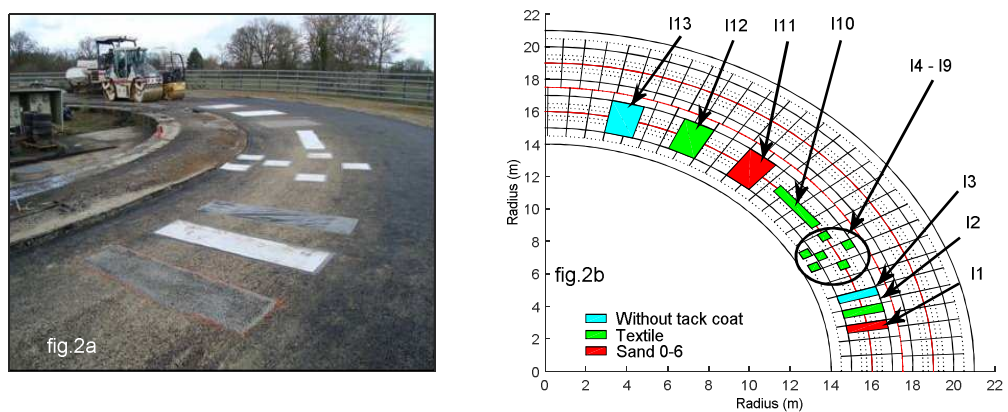

Fig. 2 2a: Interface defects before wearing course construction; 2b: Map of the different debonded areas

The pavement structure built on the existing subgrade of the test track ( $\mathrm{\approx} \approx 70 \mathrm{MPa})$ includes the following layers:

- A granular subbase consisting of unbound granular material (UGM);

- A bituminous base layer ( $8 \mathrm{~cm}$ ), consisting of Road Base Asphalt (RBA);

- A bituminous wearing course $(6 \mathrm{~cm})$, consisting of bituminous concrete (BC).

Complex modulus tests on trapezoidal specimens were performed on the two bituminous mixes. The standard elastic moduli obtained for the 2 materials at $15^{\circ} \mathrm{C}$ and $10 \mathrm{~Hz}$ were respectively $11320 \mathrm{MPa}$ (RBA) and $10700 \mathrm{MPa}(\mathrm{BC})$. Using the Huet-Sayegh visco-elastic model (Chailleux et al., 2006), infinite moduli (at very high frequency) can be extrapolated and have been estimated to $23 \mathrm{GPa}$ (RBA) and $29 \mathrm{GPa}(\mathrm{BC})$.

\section{$3 \quad$ Loading and monotoring}

The main objective of the experiment was to compare different NDT techniques based on mechanic (deflection measurement, modal testing, US wave propagation) or electromagnetic (Radar) phenomena for detecting different geometrical characteristics of artificial defects. Some results obtained with the other NDT methods are presented in papers (Simonin et al. 2013). Other objectives were to survey the defects extension during loading. This will be helpful in optimizing pavement monitoring with the different NDT methods. Investigations have been done at different stages of the experiment:

- At the beginning of the experiment (initial state);

- After 10000 loads when the structure is consolidated; 
- After 50 000, 100 000, 200 000, and 300000 loads (structure survey).

The experiment started in the spring 2012 with 100000 loads applied in April and May. At the beginning of July, 100000 loads have been applied on the debonding sector. First results show any extension of the debonding zones. So, it has been decided to apply 100000 additional loads before the end of July. Thus 300000 loads have been apply to the road. After this experiment, the fatigue machine has been transferred to another test site. However the test site with debonding area is always available to test NDT methods.

This paper presented only the results obtained with the Ultrasonic Pulse Echo (UPE) system. Tests have been performed using an antenna array (ACSYS system) which includes 24 dry-point-contact transducers. Half of them emit waves, with a central frequency equal to $55 \mathrm{kHz}$, into the structure while the others record the reflected waves. At each measurement point the antenna is apply and maintain at the road surface during few seconds. Compared with the practice on hydraulic concrete (Taffe, Wiggenhauser, 2006), the data analysis is more difficult due to attenuation of wave in the bituminous material phenomena which is enhanced at high temperature. Two antenna arrays are available and can be used one after the other, either equipped with shear S-wave transducers or compression $\mathrm{P}$-wave transducers.

Concerning the structural survey to monitor the defects extensions, the UPE Swave device was used at different test times. The UPE S-wave device was used to investigate a longitudinal profile at the $16 \mathrm{~m}$ radius above the large debonded areas (I1, I2, I3, I11, I12 \& I13). These profiles began 0.20 to $0.5 \mathrm{~m}$ before the defect and ended 0.2 to $0.5 \mathrm{~m}$ after. Measurements were made at points spaced at a distance of $0.05 \mathrm{~m}$ far from the theoretical limits of the defect and $0.02 \mathrm{~m}$ close to the limits. Moreover, three transverse profiles $1.5 \mathrm{~m}$ long has also been performed with a measurement spacing of $0.02 \mathrm{~m}$ to survey a lateral extension of the I10 textile debonded zone. Two profiles were recorded above the I10 zone and one reference profile was recorded between I10 and I11. Recorded signals show a high amplitude wave with a saturation of the signal before $50 \mu \mathrm{s}$. Then the signal is highly attenuated, and interface echoes are difficult to detect. However, the differences are significant between the signals corresponding to different defects and the one of the well bonded zone.

Regarding the mechanical characterization and the evaluation of the dynamic modulus, tests were carried out with both S-wave and P-wave devices only after 300000 cycles in July 2015. Longitudinal profiles were investigated at the $16 \mathrm{~m}$ radius above the wider debonded areas (I1, I11 and I12) with a measurement spacing of $0.05 \mathrm{~m}$. Acquisition parameters were identical in the 2 cases. The surface temperature was $28^{\circ} \mathrm{C}$. Compare to $\mathrm{S}$-wave signals, $\mathrm{P}$-wave signals have lower amplitude. This is probably due to a lower energy emits with the P-wave antenna. However a significant difference also exists between signals recorded above the different zones. 


\section{Application of the UPE}

UPE measurement can be used to detect and locate debonding zones. Measurements along each profile are presented as a B-Scan where:

- The X-coordinate is the abscissa along the road section;

- The Y-coordinate is time (UPE);

- Colors (or level of gray) represent the signal amplitude.

Figure 3 compares B-scans obtained with S-wave antenna measurements recorded on the zone I11 to I13. The colors represent the amplitude level from amplitude -100 (blue) to 100 (red). Above the debonded zone, an interface echo can be detected at around $60 \mu \mathrm{s}$. This echo is easier to locate for the debonded interfaces with sand and textile than for the interface without tack coat. The length of the debonded zone is consistent with the design and with measurement done with other NDT methods such as GPR or FWD. S-wave UPE mappings are able to detect and locate the debonded areas and to make a distinction between them.

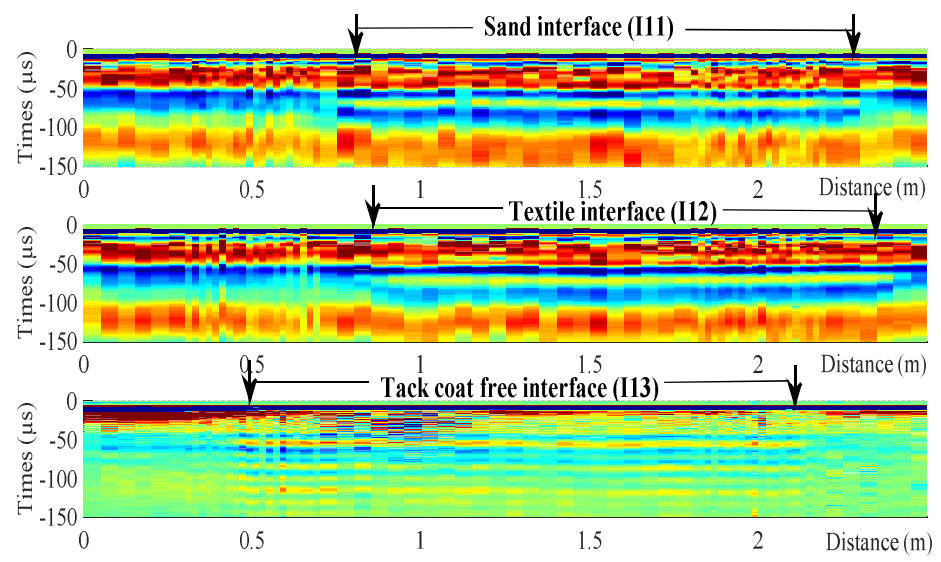

Fig. 3 B-scans of UPE (S-wave) measurements above the I11 (upper), I12 (middle) and I13 (lower) defects after 50000 loads (May 2012)

Tests performed with the UPE S-wave device during the loading phase 2012 allow detecting the different defects. B-scans were used to estimate the size of each defect. A small increase of the longitudinal defect size can be perceptible $(\approx 5 \%$ eq. $5 \mathrm{~cm}$ ) between the 10000 cycle time and the 300000 cycle time, but it remains not significant compare with the spacing with consecutive measurement point $(2$ or $5 \mathrm{~cm}$ ). The increase of the transversal profile is more significant (10 \& 20\%). The site has been preserved and it is planned to add loading (at least 500000 loads) in conjunction with other accelerated pavement testing as soon as possible. 
A second application consists to estimate the mechanical parameter of the wearing course. To do so, surface and interface echo are picked on the raw signals for both $\mathrm{S}$ and $\mathrm{P}$ wave antennas. B-scans can be helpful to locate the interface echo. Assuming the layer thickness, S-wave and P-wave velocities can be estimated from travel time picking. Using the density of the material controlled after construction $(2440 \mathrm{~kg} / \mathrm{m} 3)$ the dynamic Young's modulus $\left(\mathrm{E}_{\mathrm{dyn}}\right)$ and Poisson's ratio (v) can be evaluated at $55 \mathrm{kHz}$ and in the testing conditions at a temperature of $28^{\circ} \mathrm{C}$. These mechanical parameters have been evaluated for each signal. The Poisson's ratio is quite constant about 0.30 . The elastic modulus is about $25 \mathrm{GPa}$ outside defected zones and slightly lower above them. This value is consistent with the one of the infinite modulus around $28.9 \mathrm{GPa}$, calculated by the HuetSayegh model.

\section{Conclusions and outlooks}

Tests performed with UPE antennas have been performed on the IFSTTAR Accelerated Pavement Testing facility which includes different artificial interface defects. B-scans base on S-wave show very good sensitivity to debonded areas. The method could provide to the road engineer a picture of the internal damage of the road base and wearing course which is helpful to detect and locate damages. Signals analysis can deliver other information such as depth of defect or mechanical properties $(\mathrm{E}, \mathrm{v})$ of the wearing course.

After 300000 loads, small evolution of the interfaces has been observed with the different NDT methods including UPE. The test section will continue to be loaded in conjunction other programs on the carousel to perform at least 500000 loads. NDT tests will be continued on the pavement at regular intervals.

Future experiments will improve the data interpretation in particular taking into account the temperature and frequency effects by using the master-curve.

\section{References}

Chailleux E., Ramond G., Such C., de la Roche C., 2006, A mathematical-based mastercurve construction method applied to complex modulus of bituminous materials. Roads Materials and pavement Design 7 (EATA Special Issue): 75-92

Simonin J-M., Kerzreho J-P., Hornych P., Gouy T., 2013, Comparison of NDT method to detect debonded interfaces, 9th Int. Conf. on the Bearing Capacity of Roads, Railways and Airfiels, June 2013, Trondheim, Norway, pp. 171-180

Taffe A., Wiggenhauser H., Validation for Thickness Measurement in Civil Engineering with Ultrasonic Echo, Proceedings of Int. Symp. on NDT-CE, Saint-Louis, USA, 2006, pp506512 . 